\title{
Synthesis and intravenous infusion into the rat of glyceryl bisacetoacetate, 1-acetoacetamido-2, 3-propane diol, and partially reduced glucosyl pentaacetoacetate
}

\author{
BY RONALD H. BIRKHAHN ${ }^{1}$, ROBERT J. CLEMENS ${ }^{2}$ AND JOHN C. HUBBS ${ }^{2}$ \\ ${ }^{1}$ Department of Surgery, Medical College of Ohio, Toledo, OH, USA \\ ${ }^{2}$ Eastman Chemical Company, Kingsport, TN, USA
}

(Received 19 February 1996 - Revised 22 October 1996 - Accepted 28 October 1996)

\begin{abstract}
The efficacy of parenteral nutrition could be improved by finding a more effective energy source. Esters of short-chain fatty acids have exhibited some promise as alternatives to glucose. The present study reports on two new esters and one amide, each containing acetoacetate as the organic acid. The three compounds: glyceryl bisacetoacetate, $\mathrm{N}-2^{\prime}, 3^{\prime}$-dihydroxypropyl-3-oxo-butanamide (1acetoacetamido-2,3-propane diol), and partially reduced glucosyl pentaacetoacetate, were synthesized and then continuously infused into rats for $7 \mathrm{~d}$. The infusion rate provided $50 \%$ of the rats' estimated metabolic energy requirement, and rats were fed with a reduced-energy oral diet that provided the remaining $50 \%$ of energy plus adequate protein. Rat groups for each compound were: (1) experimental-compound-infused and ad libitum-fed, (2) isoenergetic glucose-infused and pairfed, and (3) saline infused and pair-fed. Body-weight changes, $N$ losses and $N$ retention were measured daily. All rats died from partially reduced glucosyl pentaacetoacetate infusion at $100 \%$ and $50 \%$ of the intended rate. Rats infused with 1-acetoacetamido-2,3-propane diol failed to gain weight and to increase the plasma ketone-body concentration. Glyceryl bisacetoacetate produced hyperketonaemia, and weight gain and $\mathbf{N}$ variables that were similar to those for glucose-infused rats. It was concluded that only glyceryl bisacetoacetate would make a satisfactory parenteral nutrient.
\end{abstract}

Ketone bodies: Parenteral nutrition: Synthetic nutrients

Parenteral nutrition, as currently constituted for human subjects, does not provide optimal benefit because the nutrients utilized are better suited for oral intake rather than for intravenous infusion. The two principal energy sources for parenteral nutrition are glucose and lipid emulsion, and each has shortcomings as a parenteral nutrient. Glucose oxidation is regulated by insulin and critically ill patients become insulin-resistant. Glucose is not a good metabolic fuel for such tissues as heart, red skeletal muscle, and intestine, and glucose administered parenterally elevates blood glucose, increases $\mathrm{CO}_{2}$ production, induces fatty liver, and inhibits the immune system (Birkhahn, 1982). Oxidation of longchain fatty acids is regulated by the carnitine transport system which tends to decrease in activity in the critically ill (Border et al. 1970), and long-chain fatty acids are not readily oxidized in such tissues as the brain and white skeletal muscle (Birkhahn, 1982). Parenteral lipid emulsion is not a good protein-sparing agent (Brennan et al. 1975) and provides too many $n-6$ fatty acids which can increase the inflammatory reaction, decrease immunocompetence, and fail to provide adequate energy in sepsis (Ulrich et al. 1996). These shortcomings have generated a search for other substrates to provide the energy for parenteral nutrition. The interest in improving the benefits from parenteral nutrition is attested 
by the number of alternative substances that have been tested in animals and human subjects (Hauschildt et al. 1976; Wells \& Smits, 1978; Bach \& Babayan, 1982; Holecek \& Simek, 1985; Bailey et al. 1992; Desrochers et al. 1995). A limiting factor in the testing of new substances has been the small number of suitable compounds commercially available. The possibility exists that compounds neither naturally occurring nor commercially available may be better for parenteral feeding.

A group of compounds that appear to have the best chance of meeting the needs of energy both for parenteral nutrition in general and for the critically ill in particular, are the water-soluble, synthetic esters of short C-chain organic acids which include the ketone bodies, acetoacetate and 3-hydroxybutyrate (Birkhahn \& Border, 1981; Birkhahn, 1982). Primary interest derives from the metabolic oxidation of the ketone bodies which serve as a water-soluble lipid alternative to glucose. They appear to be reciprocal to glucose, with glucose dominant in feeding and ketone bodies dominant in fasting (Cahill, 1981; Birkhahn, 1982). The oxidation and blood levels of ketone bodies are not under regulation in the same way as glucose and long-chain fatty acids. In addition, the ketone bodies can serve as metabolic fuels for all tissues except liver and erythrocytes and appear to replace glucose when the two compounds compete as energy sources. The water-soluble esters of these acids are readily hydrolysed making them a convenient means of delivering acids in a neutral system without having to deal with complications from free salts or $\mathrm{H}$ ions (Birkhahn, 1982). Generally, these compounds are not commercially available. The potential for such compounds was previously demonstrated by the long-term parenteral feeding of glyceryl monoacetoacetate (monoacetoacetin) to both normal and stressed rats (Birkhahn \& Border, 1978; Birkhahn et al. 1979, 1986, 1989; Maiz et al. 1985; Kripke et al. 1988; Nagayama et al. 1990). As a follow-up to the studies with glyceryl monoacetoacetate and for various reasons, other esters containing acetoacetate as the organic acid were synthesized for testing as parenteral nutrients.

The present report explores new acetoacetate esters. The study was undertaken with an interest both in testing different types of esters and in improving the nature of the ester used. One main objective was to find an ester with a greater percentage of acetoacetate per molecule since it is the ketone body which is of primary interest. Clemens (1984) previously reported synthesis of glucosyl pentaacetoacetate; a compound which could deliver five acetoacetate molecules and one glucose molecule per molecule of glucosyl pentaacetoacetate. It would also provide considerable energy at low osmolality which would be beneficial for increasing the energy delivery in peripheral parenteral nutrition. Unfortunately, this compound lacks water-solubility and one of our main goals was to identify compounds with good water-solubility to avoid the need for emulsification. Chemical reduction of some of the acetoacetate molecules to 3-hydroxybutyrate made the resulting compound, partially reduced glucosyl pentaacetoacetate, water-soluble and an interesting compound for trial in parenteral nutrition. In addition, the present report includes two other acetoacetate esters which were judged to be possible candidates for energy substrates in parenteral nutrition; glyceryl bisacetoacetate (diacetoacetate glycerol) which has two acetoacetates per molecule, and N-2',3'-dihydroxypropyl-3-oxo-butanamide in which $\mathrm{N}$ replaces the $\mathrm{O}$ linkage to improve stability. (Throughout the present paper, this compound will be referred to by its trivial name 1-acetoacetamido-2,3-propane diol.) The three compounds were tested in rats using a protocol similar to that previously reported (Birkhahn \& Border, 1978). The compounds in the present study, as in previous investigations, were infused alone without accompaniment of other parenteral nutrients, and animals were allowed to eat freely. The goal was to determine the toxicity and efficacy of the new compounds when given at a rate providing about $50 \%$ of the animals' needs. 
Measurement of oral food intake is one means of monitoring the efficacy of the compounds since the energy production will reduce the spontaneous energy consumption (Birkhahn et al. 1979). The possibility that incompatibilities with other parenteral nutrients could exist is recognized and such possibilities could influence the observed results. Incompatibilities could be worked out in time, but it would not be known in the initial trial if the compound was itself toxic. Even though a compound is non-toxic and well used for energy, it may be unsatisfactory for use in parenteral nutrition. Other factors come into play also, such as cost of production, stability to sterilization, and end fate of the metabolites. This investigation, like others, was to screen several candidates to determine if further work is warranted.

\section{METHODS AND MATERIALS}

\section{Chemical synthesis}

Each compound reported on in this study was extensively characterized by elemental analysis, gas chromatography-mass spectroscopy, infrared spectroscopy, nuclear magnetic resonance (NMR), molecular mass. Details can be found in USA patent 5,420,335.

Glyceryl bisacetoacetate (diglyceride of acetoacetate). Diketene $(250 \mathrm{ml})$ was slowly added over $4 \mathrm{~h}$ to a stirred solution of glycerol $(1477 \mathrm{~g})$ and dimethylaminopyridine (DMAP, $0.25 \mathrm{~g}$ ) which was maintained between $20^{\circ}$ and $30^{\circ}$ in a water-bath. The reaction mixture was stirred overnight at room temperature. On the following four working days, additional amounts of DMAP and then diketene were added as described earlier (day 2; $0.25 \mathrm{~g}$ DMAP, $500 \mathrm{ml}$ diketene: day 3; 0.25 g DMAP, $500 \mathrm{ml}$ diketene: day 4; $0.1 \mathrm{~g}$ DMAP, $740 \mathrm{ml}$ diketene: day 5; $0.1 \mathrm{~g}$ DMAP, $500 \mathrm{ml}$ diketene). The final diketene:glycerol molar ratio was $2 \cdot 01: 1$.

HPLC analysis of the crude reaction mixture revealed that the major product was glyceryl bisacetoacetate with lesser amounts of both glyceryl monoacetoacetate and trisacetoacetate.

A portion of the crude reaction mixture $(3600 \mathrm{~g})$ was dissolved in approximately 6 litres ethyl acetate and extracted with distilled water $(3 \times 3$ litres $)$ to provide a first aqueous fraction and again extracted with water $(6 \times 3$ litres $)$ to provide a second aqueous fraction. Analysis of the aqueous extracts by HPLC indicated that essentially all of the glyceryl monoacetoacetin contained in the crude reaction product was removed in the first aqueous fraction. Using a freeze-dryer, water was removed from the second aqueous fraction until constant weight was achieved (1029.5 g, approximately $30 \%)$. Without further purification, this material was tested for efficacy as a parenteral nutrient.

Proton NMR analysis of this second aqueous fraction indicated the following approximate composition: glyceryl 1,3-bisacetoacetate $58 \mathrm{~mol} \%$, glyceryl 1,2-bisacetoacetate $22 \mathrm{~mol} \%$, glyceryl trisacetoacetate $14 \mathrm{~mol} \%$, glyceryl monoacetoacetate (mixture of 1 - and 2-isomers) 6 mol \%. (Molar percentage values were obtained by measuring the integral area for easily discernible protons for each component and normalizing the area to one proton per molecule. It was assumed that the sum of the molar percentages for all identifiable components could be set to $100 \%$. Proton NMR spectra are detailed in USA patent $5,420,335$.) Field desorption mass spectrometry gave $M+1$ as 261 . The structure of glyceryl bisacetoacetate is shown in Fig. 1.

1-Acetoacetamido-2,3-propane diol. Diketene $(555 \mathrm{ml}, 7.30 \mathrm{~mol})$ was slowly added over $1.5 \mathrm{~h}$ to a solution of 1-amino-2,3-propane diol (Aldrich Chemical Co., Milwaukee, WI, USA; $666 \mathrm{~g}, 7.31 \mathrm{~mol})$ in water $(1360 \mathrm{~g})$ with the reaction temperature maintained between $25^{\circ}$ and $35^{\circ}$ with a solid $\mathrm{CO}_{2}$-ethyl acetate cooling bath. The pale yellow reaction 
<smiles>COCCOC(=O)COC(=O)OC</smiles>

(1) Glyceryl bisacetoacetate<smiles>COC(=O)COC(=O)NCC(O)CO</smiles>

(2) 1-Acetoacetamido-2,3-propane diol



(3) Partially reduced pentaacetoacetyl-glucose

Fig. 1. Chemical structures of the three compounds tested as intravenous nutrients. Compound 1: glyceryl 1,3bisacetoacetate (diglyceride of acetoacetate). That shown is the predominant substance of a mixture. Also present, but not pictured, were glyceryl 1,2-bisacetoacetate, glyceryl monoacetoacetate, and glyceryl triacetoacetate. Compound 2: 1-acetoacetamido-2,3-propane diol (monoglyceride of acetoacetamide). Compound 3: partially reduced glucosyl pentaacetoacetate. The central structure is glucose with five ketone bodies attached. The ketone-body groups were a random mixture with an average of 3.25 molecules of acetoacetate and 1.75 molecules of 3-hydroxybutyrate per molecule of glucose.

mixture was left to stir at room temperature for approximately $44 \mathrm{~h}$ before concentration in vacuo. Proton NMR of the crude reaction mixture suggested the presence of a single product of high purity $(1263 \mathrm{~g}, 99 \%$ of theoretical). This crude reaction product was crystallized from a heated $\left(65^{\circ}\right)$ solution of absolute ethanol (1 litre) and ethyl acetate (4 litres). The resulting crystals which formed on cooling $\left(25^{\circ}\right.$, overnight) were isolated and dried by suction filtration $(1002.7 \mathrm{~g}, 5.72 \mathrm{~mol}, 78 \%)$. A portion of these crystals $(754 \mathrm{~g})$ was again recrystallized from hot ethanol $(285 \mathrm{~g})$ and ethyl acetate $(2.5$ litres). The resulting crystals were filtered, washed with ethanol $(130 \mathrm{~g} / \mathrm{kg})$ in ethyl acetate $\left(25^{\circ}\right.$, 1.1 litres) and suction-dried to obtain $673.47 \mathrm{~g}$ 1-acetoacetamido-2,3-propane diol (89\% weight recovery, $70 \%$ overall yield). The melting point of 1-acetoacetamido-2,3-propane diol was $70-71^{\circ}$ and field desorption mass spectrometry gave $M_{\mathrm{r}} 175$. The structure of 1 acetoacetamido-2,3-propane diol is shown in Fig. 1.

Partially reduced glucosyl pentaacetoacetate. Glucosyl pentaacetoacetate was prepared by the method of Elam \& Middleton (1985) as follows: a partial charge of $\alpha$ D-glucose (495 g, $2.75 \mathrm{~mol}$ ) was added to a stirred solution of distilled 2,2,6-trimethyl-4H1,3 -dioxinone $(3414 \mathrm{~g}, 23.73 \mathrm{~mol})$ at $50^{\circ}$. The resulting heterogeneous solution was heated to $110^{\circ}$, and the remainder of the $\alpha$-D-glucose was added ( $360 \mathrm{~g}, 2.00 \mathrm{~mol}$ ). The reaction 
mixture was heated to between $90^{\circ}$ and $110^{\circ}$ for $3 \mathrm{~h}$ and $15 \mathrm{~min}$ with continuous removal of acetone. During the course of the reaction, the solution became homogeneous. Heating was discontinued and the reaction was allowed to cool to room temperature overnight. Proton NMR analysis revealed the presence of glucosyl pentaacetoacetate and traces of acetone, dehydroacetic acid and 2,2,6-trimethyl-4H-1,3-dioxinone. A portion (1898 $\mathrm{g}$ ) of the crude reaction product $(2839 \mathrm{~g}, 99.6 \%)$ was purified (in $200-250 \mathrm{~g}$ portions) by dissolving in warm $\left(75-80^{\circ}\right)$ absolute ethanol (88-90\% ethanol by weight). On cooling to room temperature, the product precipitated as an oil. The resulting oil was swirled at $80^{\circ}$ for $5 \mathrm{~min}$ in the presence of absolute ethanol $(800 \mathrm{~g})$. On cooling to room temperature, the product was isolated by decantation of the ethanol phase. The product $(1370 \mathrm{~g})$ was dried under vacuum overnight. Glucosyl pentaacetoacetate was shown to be the only product by NMR integration. The composition was approximately $78 \%$ pentaacetoacetyl- $\alpha$-D-glucose and $22 \%$ pentaacetoacetyl- $\beta$-D-glucose.

Raney nickel ( $25 \mathrm{~g}, \mathrm{~W}-2$ grade, methanol wet) was added to pentaacetoacetyl glucose $(392.6 \mathrm{~g}, 0.654 \mathrm{~mol})$ dissolved in ethyl acetate $(520.4 \mathrm{~g})$. The mixture was placed in a high pressure vessel and stirred magnetically for $8 \mathrm{~h}$ under an atmosphere of $20700 \mathrm{kPa} \mathrm{H}_{2}$. The reaction vessel was then depressurized, flushed with $\mathrm{N}_{2}$, and the contents removed. More Raney nickel ( $25 \mathrm{~g}$ ) was added to the reaction mixture, and the mixture was reintroduced into the high pressure vessel. The contents of the high pressure vessel were stirred at $20700 \mathrm{kPa} \mathrm{H}_{2}$ pressure for an additional $24 \mathrm{~h}$. The contents were again removed, and proton NMR analysis indicated approximately $41 \%$ reduction in the intensity of acetoacetyl peaks (methyl groups). The resulting material was completely miscible with water in all proportions.

A second sample of glucosyl pentaacetoacetate $(393.4 \mathrm{~g})$ was reduced as described earlier until a $31 \%$ reduction in acetoacetyl proton NMR resonances was achieved.

The two reduced samples were combined, filtered through celite, and concentrated in vacuo overnight. The resulting material $(708.88 \mathrm{~g})$ was dissolved in distilled, Millipore filtered water ( 2 litres) and passed through a $90 \mathrm{~mm}$ (i.d.) glass column containing a mixed bed ion exchange resin (450 g, Bio-Rad AG-501X8 (D), Bio-Rad Laboratories, Hercules, CA, USA). The eluate was concentrated to constant weight $(597.6 \mathrm{~g})$ in a freeze-dryer. Proton NMR indicated that between 35 and $38 \%$ of the acetoacetates had been reduced to hydroxybutyrates. Fast atom bombardment mass spectrometry gave $M_{\mathrm{r}} 602,604,606$ for 1 , 2 and 3 reduced acetoacetates respectively. The structure of partially reduced glucosyl pentaacetoacetate is shown in Fig. 1.

\section{Protocol}

Eighty-two male Sprague-Dawley rats (Harlan Sprague-Dawley, Indianapolis, IN, USA) with body weights $175-200 \mathrm{~g}$ were housed in a well-ventilated, limited access area with a controlled $12 \mathrm{~h}$ light-dark cycle. This area is part of the Division of Laboratory Animal Medicine at the Medical College of Ohio at Toledo which is under the direction of a doctor of veterinary medicine. The protocol for this investigation was reviewed and approved by the Institutional Animal Care and Use Committee (IACUC) of the Medical College of Ohio. Water was available ad libitum at all times throughout the experimental periods. Rats were adapted to the animal unit for at least $4 \mathrm{~d}$ before the experiment was started and were housed in individual metabolic cages altered for continuous intravenous feeding throughout their stay in the animal unit.

Animals were pretreated for infusion protocols by being anaesthetized with ketamine hydrochloride $(100 \mathrm{mg} / \mathrm{kg}$ body weight, Ketoject, Bristol Laboratories, Syracuse, NY, 
USA) and having a plastic backbutton sewn onto the skin at the nape of the neck with continuous suturing. The rats were maintained in the metabolic cage and fed on solid rat food for $4 \mathrm{~d}$. The oral food was then switched to a complete liquid rat diet (no. $711 \mathrm{C}$, BioServ, Inc., Frenchtown, NJ, USA) for $3 \mathrm{~d}$. This $7 \mathrm{~d}$ period allowed the rats to adjust to wearing the backbutton. Each rat was monitored daily for weight gain and food intake during the pretreatment period, and any animal that failed to gain weight or eat properly was removed from the study.

On day 7 , each rat was again given general anaesthesia as described earlier and surgically prepared for continuous intravenous infusion by placing a silastic catheter in the external jugular vein as previously described (Birkhahn et al. 1979). Animals were allowed a minimum of $3 \mathrm{~d}$ to recover from surgery, and food intake and body weight were monitored to ensure adequate growth before the infusion was commenced. Catheters were kept patent by infusing saline $(9 \mathrm{~g} \mathrm{NaCl} / \mathrm{l})$ at $25 \mathrm{ml} / \mathrm{d}$, and rats were maintained on the complete oral liquid diet.

On day 0 , rats were divided among three protocols: for testing glyceryl bisacetoacetate, $n$ 32; for testing 1-acetoacetamido-2,3-propanediol, $n$ 30; and for testing partially reduced glucosyl pentaacetoacetate, $n$ 20. Rats in each protocol were further subdivided into three weight-matched groups which were distinguished by the parenteral infusion which they received. The solutions and protocols used are detailed later.

The group receiving each experimental compound was compared with groups of animals receiving either isoenergetic glucose or non-energetic saline while being pair-fed to the animals receiving the experimental compound. Animals receiving saline were infused at the rate of $50 \mathrm{ml} / \mathrm{d}$ throughout the investigation period. Rats receiving glucose were infused with a solution containing $160 \mathrm{~g}$ glucose $/ 1$ which was prepared by diluting $320 \mathrm{ml} 500 \mathrm{~g} / \mathrm{l}$ glucose to $1000 \mathrm{ml}$ using saline solution $(9 \mathrm{~g} \mathrm{NaCl} / 1)$. These rats were infused at a rate of $50 \mathrm{ml} / \mathrm{d}$ to provide them with $8 \mathrm{~g}$ glucose/d. The experimental solutions were prepared by adding $125 \mathrm{~g}$ glyceryl bisacetoacetate, $112 \mathrm{~g}$ 1-acetoacetamido-2,3propane diol, or $135 \mathrm{~g}$ partially reduced glucosyl pentaacetoacetate to sufficient saline $(9 \mathrm{~g}$ $\mathrm{NaCl} / 1$ ) to produce a total volume of $1000 \mathrm{ml}$. The solution was sterilized by passage through a $0.22 \mu \mathrm{m}$ filter and infused continuously. Each rat receiving an experimental compound was infused with a solution containing a calculated $2093 \mathrm{~kJ} / 1(540 \mathrm{kcal} / \mathrm{l})$ and was infused at $50 \mathrm{ml} / \mathrm{d}$ to provide $113 \mathrm{~kJ} / \mathrm{d}(27 \mathrm{kcal} / \mathrm{d})$ which was estimated to be approximately $50 \%$ of the rat's daily energy requirement.

The glyceryl bisacetoacetate infusion protocol used fourteen rats receiving glyceryl bisacetoacetate, nine rats receiving glucose, and nine rats receiving saline.

The 1-acetoacetamido-2,3-propane diol infusion protocol used ten rats receiving 1acetoacetamido-2,3-propane diol, ten rats receiving glucose, and ten rats receiving saline.

The partially reduced glucosyl pentaacetoacetate infusion protocol used ten rats receiving partially reduced glucosyl pentaacetoacetate, five rats receiving glucose, and five rats receiving saline.

All rats were fed on a low-energy, normal-protein diet throughout the experimental period. Animals infused with experimental compound were fed ad libitum, and glucoseand saline-infused rats were pair-fed with animals receiving experimental compound in that treatment regimen. The low-energy liquid diet contained protein, electrolytes, vitamins, trace minerals, and fat equivalent to the complete liquid diet fed to the rats in the adaptation phase. Carbohydrate was removed to reduce the amount of energy per volume in the liquid.

Parenteral infusate volume, oral food intake, body weight, and urine volume were monitored daily for each rat over the $7 \mathrm{~d}$ infusion period. Volume of compound infused and 
food intake were determined daily by measuring containers before and after each $24 \mathrm{~h}$ period. Urine was collected over a $24 \mathrm{~h}$ period, and total urinary $\mathrm{N}$ was measured by pyrochemiluminescence as previously described (Birkhahn \& Robertson, 1984). At the end of $7 \mathrm{~d}$ of infusion, rats were killed by decapitation, and the neck blood was collected in chilled tubes containing dried heparin. The plasma was assayed for ketone bodies, glucose, and free fatty acids as previously reported (Birkhahn et al. 1979). The visceral organs were inspected for gross lesions, and the liver was removed and weighed.

The data were analysed for significance by one-way ANOVA with repeated measures for comparing daily response to diet. Student-Newman-Keuls multiple comparison test was done post hoc on the one-way analysis for a day-by-day comparison of the three curves. Data collected on day 7 , such as liver weight and plasma concentrations, were analysed by one-way ANOVA followed by the Student-Newman-Keuls test if the data were shown to have equal variance (Levene Median test) and to pass the normality test (Kolmogorov-Smirnov test). If either test failed, then the data were analysed by the nonparametric Kruskal-Wallis ANOVA on ranks (Glantz, 1992). The null hypothesis was concluded to be invalid if $P \leq 0 \cdot 05$. The data analyses were carried out using SigmaStat (version 1.01 for DOS, Jandel Scientific, San Rafael, CA, USA).

\section{RESULTS}

\section{Infusion of partially reduced glucosyl pentaacetoacetate}

Partially reduced glucosyl pentaacetoacetate was a slightly pink oil with a molecular mass of $604 \mathrm{Da}$ (for two reduced acetoacetates) and was totally miscible with water in all proportions. An energy density of $16.67 \mathrm{~kJ} / \mathrm{g}(4.0 \mathrm{kcal} / \mathrm{g})$ was estimated from available molar heats of combustion based on 1 mol glucose, 3 mol acetoacetate, and 2 mol 3hydroxybutyrate per mol partially reduced glucosyl pentaacetoacetate.

The initial trial involved five experimental rats infused at the rate of $50 \mathrm{ml} / \mathrm{d}$, and all five were found dead at the end of $24 \mathrm{~h}$. Apparently, all had died early since there was no urine output. Visible skin, feet and tail were bright red suggesting subcutaneous bleeding and diffuse haemolysis of erythrocytes.

Five more rats were infused with the experimental compound at a rate of $25 \mathrm{ml} / \mathrm{d}$ (half the previous intake). Three rats were dead at $24 \mathrm{~h}$ and two survived until $24 \mathrm{~h}$. However, the two surviving rats had catheter leaks, and the amount of solution they actually received was not known. The leaks were repaired at $24 \mathrm{~h}$ and the rats were dead at $48 \mathrm{~h}$.

\section{Infusion of 1-acetoacetamido-2,3-propane diol}

1-Acetoacetamido-2,3-propane diol was a white solid with a molecular mass of $175 \mathrm{Da}$ and

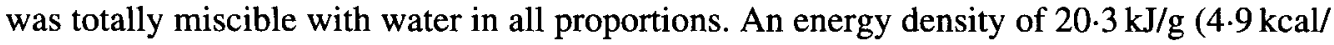
g) was estimated from thermodynamic data of similar compounds.

A total of thirty rats were started on this protocol, and three rats were lost before completion. Consequently, the final animal count was nine rats infused with 1acetoacetamido-2,3-propane diol, nine rats infused with glucose, and nine rats infused with saline.

Necropsy was conducted on each rat after blood collection and liver removal. The visceral organs including the liver were grossly inspected for the presence of abnormalities which might indicate an adverse reaction to the compound. The organs of all rats appeared normal and free of gross abnormalities. 


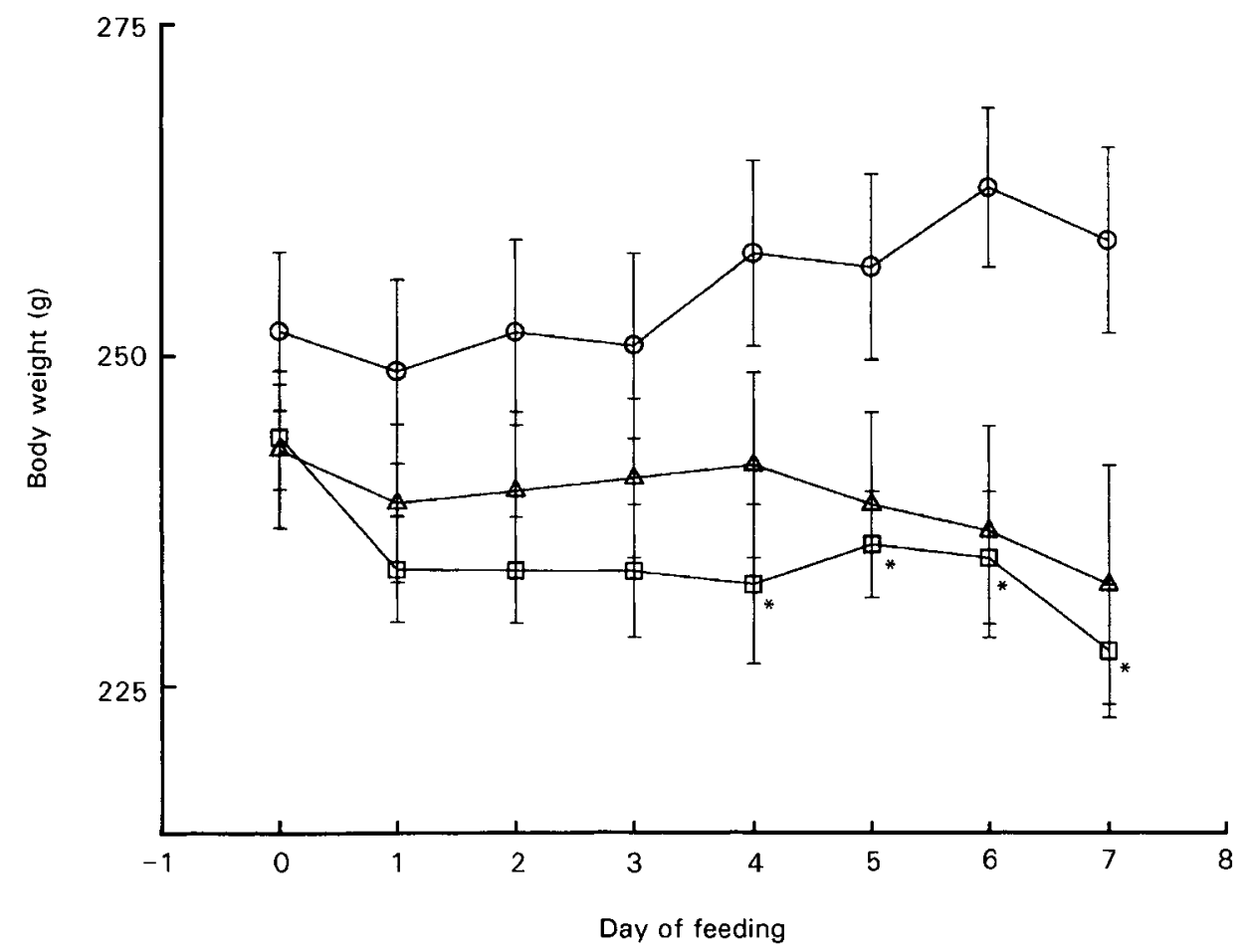

Fig. 2. Daily body weights for groups of rats used to evaluate 1-acetoacetamido-2,3-propane diol infusion for $7 \mathrm{~d}$. Rats were infused with: $(O)$, glucose, $(\square)$, 1-acetoacetamido-2,3-propane diol or $(\triangle)$, saline. Values are means for all surviving rats in a group with their standard errors represented by vertical bars. ${ }^{*}$ Mean values were significantly different from those for the group infused with glucose in day-by-day analysis, $P<0.05$.

Fig. 2 illustrates the daily body-weight changes for the three groups of rats included in this protocol. Rats on the combination of oral feeding and glucose infusion had a tendency to maintain their body weight while rats infused with saline and 1-acetoacetamido-2,3propane diol lost weight. The magnitude of the weight loss was similar for the saline and 1acetoacetamido-2,3-propane diol infused rats.

Fig. 3 shows the daily $\mathrm{N}$ intake for the three groups of rats included in this protocol. The $\mathrm{N}$ intake for glucose- and saline-infused rats was limited to that in the oral liquid diet but for rats infused with 1-acetoacetamido-2,3-propane diol it consisted of that from the oral, liquid diet and that from the 1-acetoacetamido-2,3-propane diol. Dietary $\mathrm{N}$ via oral intake was similar for the three groups as shown by the solid lines in Fig. 3 while the dotted line indicates the total $\mathrm{N}$ intake by 1 -acetoacetamido-2,3-propane diol-infused rats. The latter was significantly greater than the dietary $\mathrm{N}$ since 1 -acetoacetamido-2,3-propane diol is $8 \% \mathrm{~N}$. At an infusion rate of $5.6 \mathrm{~g} / \mathrm{d}$, these rats received approximately $450 \mathrm{mg} \mathrm{N}$ in the form of 1-acetoacetamido-2,3-propane diol.

Fig. 4 shows the daily $24 \mathrm{~h}$ urinary total $\mathrm{N}$ excreted by the three treatment groups in this protocol. The saline-infused rats lost significantly more $\mathrm{N}$ than did the glucose-infused rats, demonstrating the effectiveness of the supplemental glucose infusion to assist in the retention of $\mathrm{N}$. Rats infused with 1-acetoacetamido-2,3-propane diol lost about $350 \mathrm{mg}$ more $\mathrm{N}$ than did the saline-infused rats and about $400 \mathrm{mg}$ more $\mathrm{N}$ than did the glucoseinfused rats. The difference in $\mathrm{N}$ loss was approximately $90 \%$ of the $\mathrm{N}$ infused as 1 acetoacetamido-2,3-propane diol. 


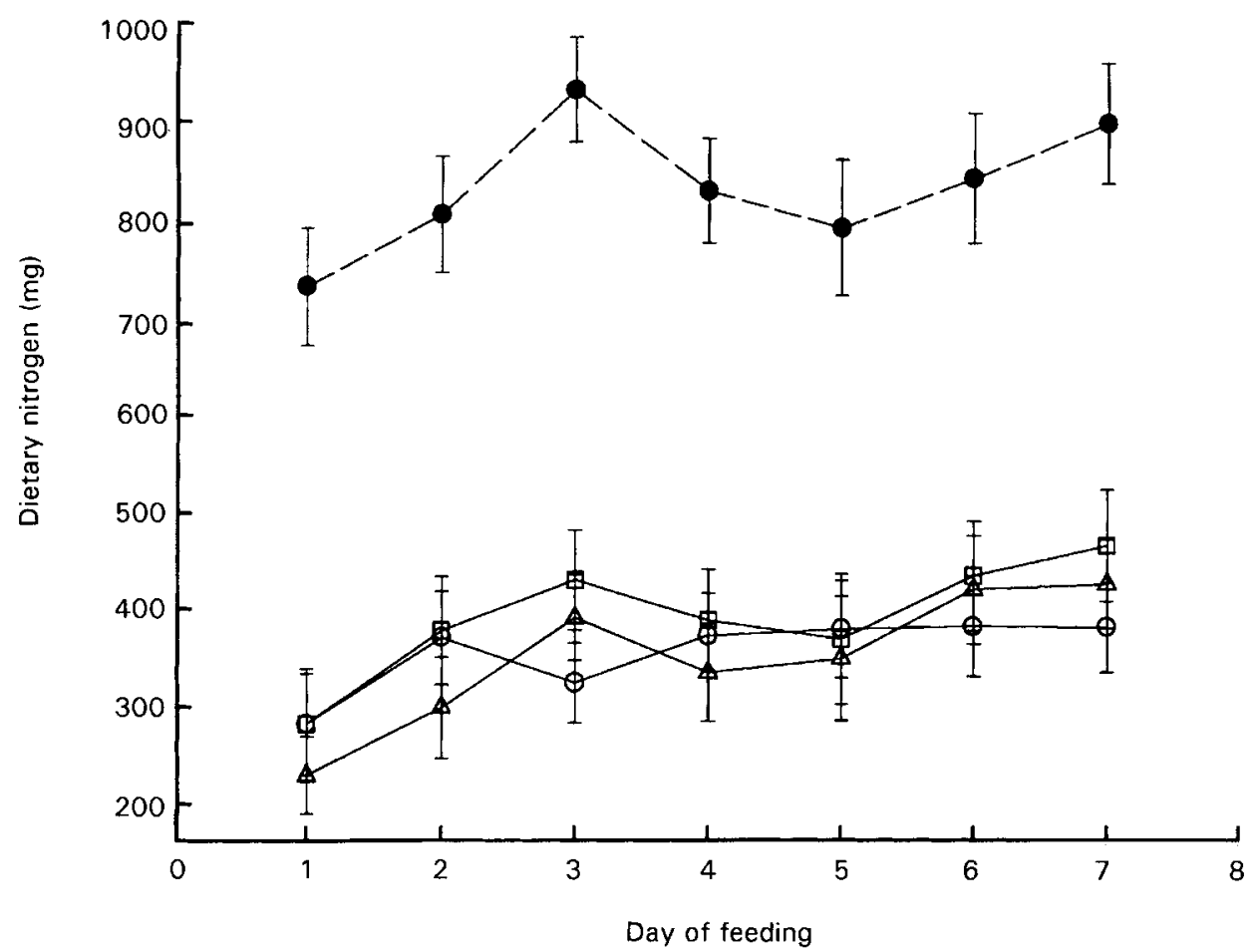

Fig. 3. Daily nitrogen intake by groups of rats used to evaluate 1-acetoacetamido-2,3-propane diol infusion for $7 \mathrm{~d}$. The groups received a low-energy rat diet together with: $(O)$, glucose, $(\square)$, 1-acetoacetamido-2,3-propane diol (oral), $(\triangle)$, saline or (O), 1-acetoacetamido-2,3-propane diol (oral + intravenous). Values are means for all surviving rats in a group with their standard errors represented by vertical bars.

Fig. 5 presents the daily $\mathrm{N}$ balance, defined as the difference between the $\mathrm{N}$ intake and urinary $\mathrm{N}$ output, for the three groups included in this protocol. Glucose-infused rats had a significantly greater $\mathrm{N}$ balance than did the saline-infused rats. The daily $\mathrm{N}$ balance curve for the 1-acetoacetamido-2,3-propane diol-infused rats was significantly greater than the daily $\mathrm{N}$ balance for glucose-infused rats. The difference ranged from 50 to $100 \mathrm{mg} / \mathrm{d}$.

The results of measuring the liver and plasma glucose, ketone bodies and free fatty acids are provided in Table 1 . The average liver weight was similar for all three treatment groups. Plasma glucose level was significantly higher, and plasma ketone-body concentration significantly lower in the glucose-infused group than the other two groups. All variables presented in Table 1 were similar for rats infused with 1-acetoacetamido-2,3propane diol and saline.

\section{Infusion of glyceryl bisacetoacetate}

A total of twenty-nine rats were initially entered into this protocol and eight were lost for a variety of technical reasons. The final rat count for averages presented in the results was, therefore, seven rats infused with glyceryl bisacetoacetate, seven rats infused with glucose, and seven rats infused with saline.

The glyceryl bisacetoacetate composition was approximately $58 \mathrm{~mol} \%$ glyceryl 1,3bisacetoacetate, $22 \mathrm{~mol} \%$ glyceryl 1,2-bisacetoacetate, $14 \mathrm{~mol} \%$ glyceryl trisacetoacetate 


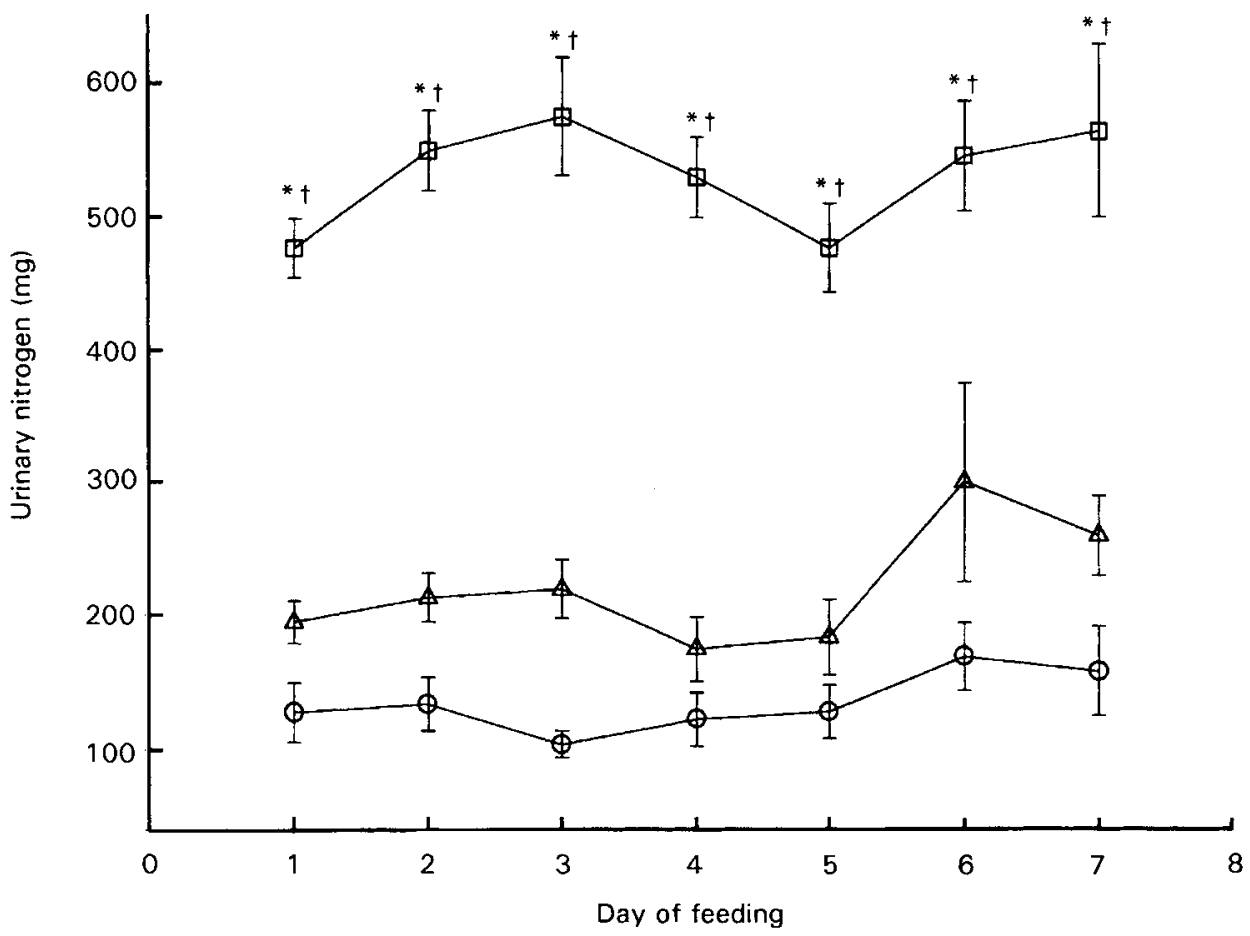

Fig. 4. Daily 24 h urinary nitrogen losses for groups of rats used to evaluate 1-acetoacetamido-2,3-propane diol infusion for $7 \mathrm{~d}$. Rats were infused with: $(O)$, glucose, $(\square), 1$-acetoacetamido-2,3-propane diol or $(\Delta)$, saline. Values are means for all surviving rats in a group, with their standard errors represented by vertical bars. Mean values were significantly different from those for the group infused with: * glucose or †saline in day-by-day analysis, $P<0.05$.

Table 1. Liver weight and plasma concentrations of various metabolites in rats after $7 d$ parenteral infusion of 1-acetoacetamido-2,3-propane diol (experimental compound)

(Values are means with their standard errors)

\begin{tabular}{|c|c|c|c|c|c|c|}
\hline \multirow[t]{2}{*}{$\begin{array}{l}\text { Group ... } \\
\text { Infusate... }\end{array}$} & \multicolumn{2}{|c|}{$\begin{array}{c}\text { A } \\
\text { Glucose }\end{array}$} & \multicolumn{2}{|c|}{$\begin{array}{c}\text { B } \\
\text { Experimental } \\
\text { compound }\end{array}$} & \multicolumn{2}{|c|}{$\begin{array}{c}\mathrm{C} \\
\text { Saline }\end{array}$} \\
\hline & Mean & $\mathrm{SE}$ & Mean & SE & Mean & SE \\
\hline No. of rats & \multicolumn{2}{|c|}{9} & \multicolumn{2}{|c|}{9} & \multicolumn{2}{|c|}{9} \\
\hline Liver wt (g) & 9.4 & 0.4 & 8.8 & $0-4$ & $8 \cdot 2$ & 0 . \\
\hline Liver (g/kg BW) & 36 & 2 & 39 & 2 & 35 & 2 \\
\hline \multicolumn{7}{|l|}{ Plasma: } \\
\hline $\mathrm{FFA}(\mu \mathrm{mol} / \mathrm{l})$ & 341 & 40 & 580 & 113 & 499 & 60 \\
\hline Glucose $(\mathrm{mmol} / \mathrm{l})$ & $2140^{\mathrm{a}}$ & 330 & $1090^{\mathrm{b}}$ & 50 & $1200^{\mathrm{b}}$ & 50 \\
\hline $\mathrm{ACAC}(\mu \mathrm{mol} / \mathrm{l})$ & $29^{\mathrm{a}} \dagger$ & 18 & $195^{\mathrm{b}} t$ & 41 & $141^{\mathrm{b}}$ & 28 \\
\hline $\mathrm{BOHB}(\mu \mathrm{mol} / 1)$ & $512^{\mathrm{a}}$ & 53 & $897^{b}$ & 110 & $689^{\mathrm{ab}}$ & 82 \\
\hline Total ketones $(\mu \mathrm{mol} / /)$ & $532^{\mathrm{a}}$ & 55 & $1071^{\mathrm{b}}$ & 146 & $830^{\mathrm{ab}}$ & 101 \\
\hline
\end{tabular}

FFA, free fatty acids; ACAC, acetoacetate; $\mathrm{BOHB}, \beta$-hydroxybutyrate; $\mathrm{BW}$, body weight.

${ }^{\mathrm{a}, \mathrm{b}}$ Mean values within a row not sharing a common superscript letter were significantly different, $P<0.05$ (ANOVA, using the Newman-Keuls post hoc test).

$* n 6$.

$+n 5$. 




Fig. 5. Daily nitrogen balance, defined as the difference between the total nitrogen intake and urinary nitrogen losses, for groups of rats used to evaluate 1-acetoacetamido-2,3-propane diol infusion for $7 \mathrm{~d}$. Rats were infused with: $(\mathrm{O})$, glucose, $(\square)$, 1-acetoacetamido-2,3-propane diol or $(\triangle)$, saline. Values are means for all surviving rats in a group, with their standard errors represented by vertical bars. Mean values were significantly different from those for the group infused with: *glucose or $\dagger$ saline in day-by-day analysis, $P<0.05$.

(triacetoacetate glycerol), and less than $6 \mathrm{~mol} \%$ glyceryl monoacetoacetate, and the mixture was totally water-soluble. The molecular mass and energy data for each component are listed in Table 2. The average energy density for all components was estimated as $18.1 \mathrm{~kJ} / \mathrm{g}(4.3 \mathrm{kcal} / \mathrm{g})$ using heats of combustion for glycerol and acetoacetate. One mol of experimental compound would provide approximately $2 \mathrm{~mol}$ acetoacetate and 1 mol glycerol on complete hydrolysis.

Daily changes in body weight for each rat group are illustrated in Fig. 6 The steady weight loss by rats infused with saline indicated that the oral dietary intake was inadequate to support growth or weight maintenance. The body-weight curves, analysed as total curves, for glyceryl bisacetoacetate- and glucose-infused rats were similar. Day-by-day analysis showed that the weights were significantly different only on day 5 .

The average dietary $\mathrm{N}$ intake for each rat group is illustrated in Fig. 7. Rats were pairfed throughout the infusion period, and this is reflected by the similar curves of dietary $\mathrm{N}$ intakes for the three groups.

The average daily urinary $\mathrm{N}$ excretion for each of the three treatment groups is depicted in Fig. 8. Urinary $\mathrm{N}$ output by glyceryl bisacetoacetate- and glucose-infused rats was similar throughout the $7 \mathrm{~d}$ study whether the data were analysed day by day or curve $v$. curve. In contrast, saline-infused rats excreted significantly more urinary $N$ on days 4-6 than did rats on the other two treatments when analysed day by day. The urinary $\mathrm{N}$ loss 
Table 2. Energy density calculation for the mixture of compounds that made up glyceryl bisacetoacetate

\begin{tabular}{lcccc}
\hline \hline Compound & Molecular mass (Da) & Mol \%* & $\mathrm{kJ} / \mathrm{g}$ & $(\mathrm{kcal} / \mathrm{g}) \dagger$ \\
\hline Glyceryl 1,3-bisacetoacetate & 260 & 58 & $18 \cdot 1$ & $(4 \cdot 33)$ \\
Glyceryl 1,2-bisacetoacetate & 260 & 22 & $18 \cdot 1$ & $(4 \cdot 33)$ \\
Glyceryl trisacetoacetate & 344 & 14 & $18 \cdot 1$ & $(4.33)$ \\
Glyceryl monoacetoacetate & 176 & 6 & $18 \cdot 0$ & $(4.32)$ \\
\hline
\end{tabular}

* The mol \% values are approximate and derived from nuclear magnetic resonance data.

$\dagger$ Energy values were determined from thermodynamic heats of combustion for glycerol and acetoacetate.

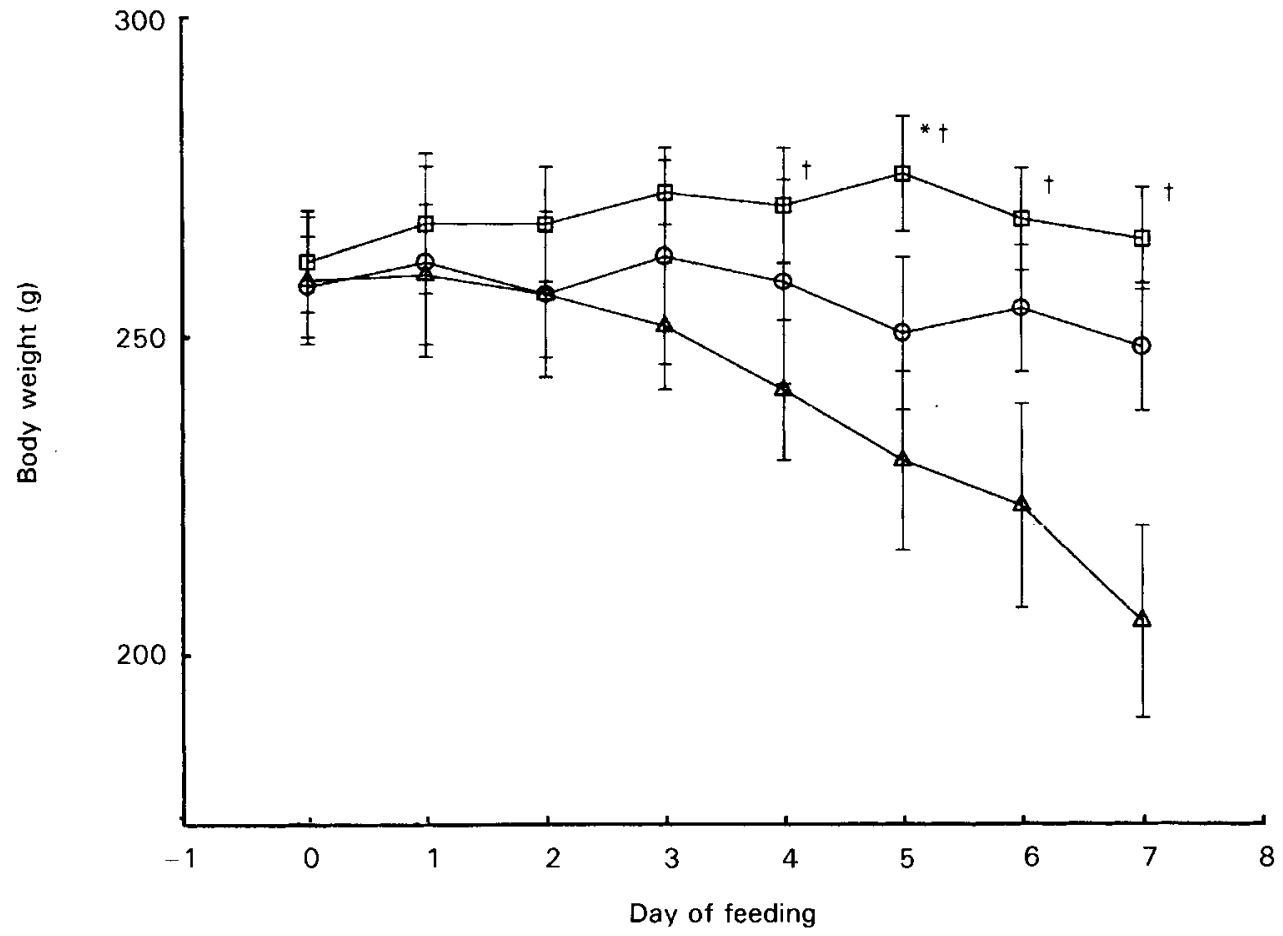

Fig. 6. Daily body weights for groups of rats used to evaluate glyceryl bisacetoacetate infusion for $7 \mathrm{~d}$. Rats were infused with: $(O)$, glucose, $(\square)$, glyceryl bisacetoacetate or $(\triangle)$, saline. Values are means for all surviving rats in a group, with their standard errors represented by vertical bars. Mean values were significantly different from those for the group infused with: *glucose or $\uparrow$ saline in day-by-day analysis, $P<0.05$.

curve for saline-infused rats was significantly greater than those for the other two treatments.

The average $\mathrm{N}$ balance, defined as the difference between $\mathrm{N}$ intake and urinary $\mathrm{N}$ output, is graphically displayed in Fig. 9. Saline-infused rats exhibited only marginally positive $\mathrm{N}$ balance over the $7 \mathrm{~d}$ study. This demonstrated that the oral dietary intake was not adequate. The $\mathrm{N}$ balance curves for glyceryl bisacetoacetate- and glucose-infused rats were significantly greater than the curve for saline-infused rats. A day-by-day analysis showed that the glyceryl bisacetoacetate rats had a more positive $\mathrm{N}$ balance than the salineinfused rats on all days except day 1 . The glucose- and glyceryl bisacetoacetate-infused 




Fig. 7. Daily nitrogen intake by groups of rats used to evaluate glyceryl bisacetoacetate infusion for $7 \mathrm{~d}$. Rats were infused with: $(O)$, glucose, $(\square)$, glyceryl bisacetoacetate or $(\triangle)$, saline. Values are means for all surviving rats in a group, with their standard errors represented by vertical bars.

rats had similar $\mathrm{N}$ balance curves although a day-by-day analysis showed a more positive $\mathrm{N}$ balance for the glyceryl bisacetoacetate-infused rats on days 3, 4 and 5 .

Table 3 lists the liver weight, liver weight $/ \mathrm{kg}$ body weight, and the plasma free fatty acids, glucose, and ketone bodies. The total and relative liver weights were similar for glucose- and glyceryl bisacetoacetate-infused rats, and both treatment groups had larger livers than did saline-infused rats. Plasma free fatty acids were similar for all treatment groups. Glyceryl bisacetoacetate-infused rats had the highest plasma ketone body concentrations, and the other two groups had similar concentrations. Plasma glucose was different among the three treatment groups. Glucose-infused rats had the highest plasma glucose concentration, and saline-infused rats had the lowest concentration.

\section{DISCUSSION}

The acute toxicity and lethality of partially reduced glucosyl pentaacetoacetate was unexpected and disappointing. It was anticipated that this compound might deliver more energy at lower osmolality while still permitting the use of a water-soluble system. Partially reduced glucosyl pentaacetoacetate offers 5 mol ketone bodies, 1 mol glucose, and $10036 \mathrm{~kJ}(2402 \mathrm{kcal})$ per mol compound. In comparison, glyceryl monoacetoacetate provides only $1 \mathrm{~mol}$ acetoacetate, $1 \mathrm{~mol}$ glycerol, and $3175 \mathrm{~kJ}(760 \mathrm{kcal})$ per mol compound. Partially reduced glucosyl pentaacetoacetate was not our first compound to be acutely lethal, since glyceryl monopropionate was also acutely lethal (Birkhahn \& Border, 1981). In that case the problem could be identified as rapid formation of excess lactic acid. In the current situation, it could not be ascertained whether the lethality resulted from a 


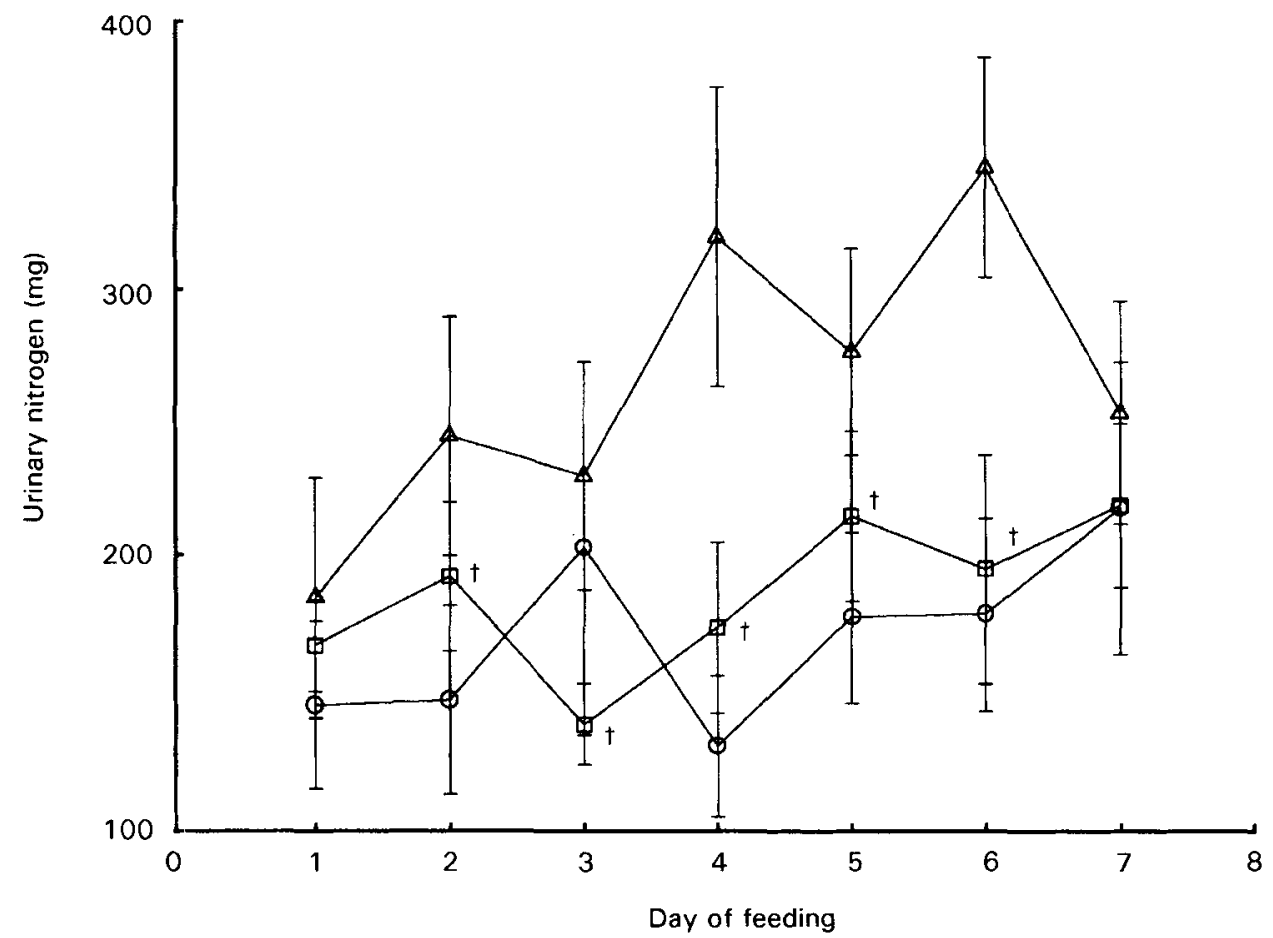

Fig. 8. Daily $24 \mathrm{~h}$ urinary nitrogen losses for groups of rats used to evaluate glyceryl bisacetoacetate infusion for $7 \mathrm{~d}$. Rats were infused with: $(O)$, glucose, $(\square)$, glyceryl bisacetoacetate or $(\triangle)$, saline. Values are means for all surviving rats in a group, with their standard errors represented by vertical bars. $†$ Mean values were significantly different from those for the group infused with saline in day-by-day analysis, $P<0.05$.

Table 3. Liver weight and plasma concentrations of various metabolites in rats after $7 d$ parenteral infusion of glyceryl bisacetoacetate (experimental compound)

(Values are means with their standard errors)

\begin{tabular}{|c|c|c|c|c|c|c|}
\hline \multirow[t]{2}{*}{$\begin{array}{l}\text { Group ... } \\
\text { Infusate... }\end{array}$} & \multicolumn{2}{|c|}{$\begin{array}{c}\mathrm{A} \\
\text { Glucose }\end{array}$} & \multicolumn{2}{|c|}{ B } & \multicolumn{2}{|c|}{$\begin{array}{c}\mathrm{C} \\
\text { Saline }\end{array}$} \\
\hline & Mean & SE & Mean & SE & Mean & $\mathrm{SE}$ \\
\hline No. of rats & \multicolumn{2}{|c|}{7} & \multicolumn{2}{|c|}{7} & \multicolumn{2}{|c|}{7} \\
\hline Liver wt (g) & $8 \cdot 0^{2}$ & 0.4 & $8 \cdot 6^{\mathrm{a}}$ & 0.6 & $4 \cdot 8^{b}$ & 0.6 \\
\hline Liver $(\mathrm{g} / \mathrm{kg} \mathrm{BW})$ & $32^{\mathrm{a}}$ & 2 & $32^{\mathrm{a}}$ & 2 & $23^{\mathrm{b}}$ & 2 \\
\hline \multicolumn{7}{|l|}{ Plasma: } \\
\hline $\mathrm{FFA}(\mu \mathrm{mol} / \mathrm{l})$ & $564^{\mathrm{a}}$ & 11 & $563^{a}$ & 4 & $458^{b}$ & 10 \\
\hline Glucose $(\mathrm{mmol} / \mathrm{l})$ & $1850^{2}$ & 140 & $1170^{\mathrm{b}}$ & 110 & $880^{\mathrm{c}}$ & 170 \\
\hline $\mathrm{ACAC}(\mu \mathrm{mol} / 1)$ & $88^{\mathrm{a}}$ & 29 & $716^{b}$ & 95 & $172^{\mathrm{a}}$ & 54 \\
\hline BOHB $(\mu \mathrm{mol} / \mathrm{l})$ & $505^{\mathrm{a}}$ & 101 & $776^{\mathrm{b}}$ & 91 & $558^{\mathrm{a}}$ & 208 \\
\hline Total ketones $(\mu \mathrm{mol} / 1)$ & $593^{\mathrm{a}}$ & 124 & $1492^{b}$ & 165 & $729^{\mathrm{a}}$ & 259 \\
\hline
\end{tabular}

BW, body weight; FFA, free fatty acids; ACAC, acetoacetate; BOHB, $\beta$-hydroxybutyrate.

a,b,c Mean values within a row not sharing a common superscript letter were significantly different, $P<0.05$ (ANOVA, using the Newman-Keuls post-hoc test). 


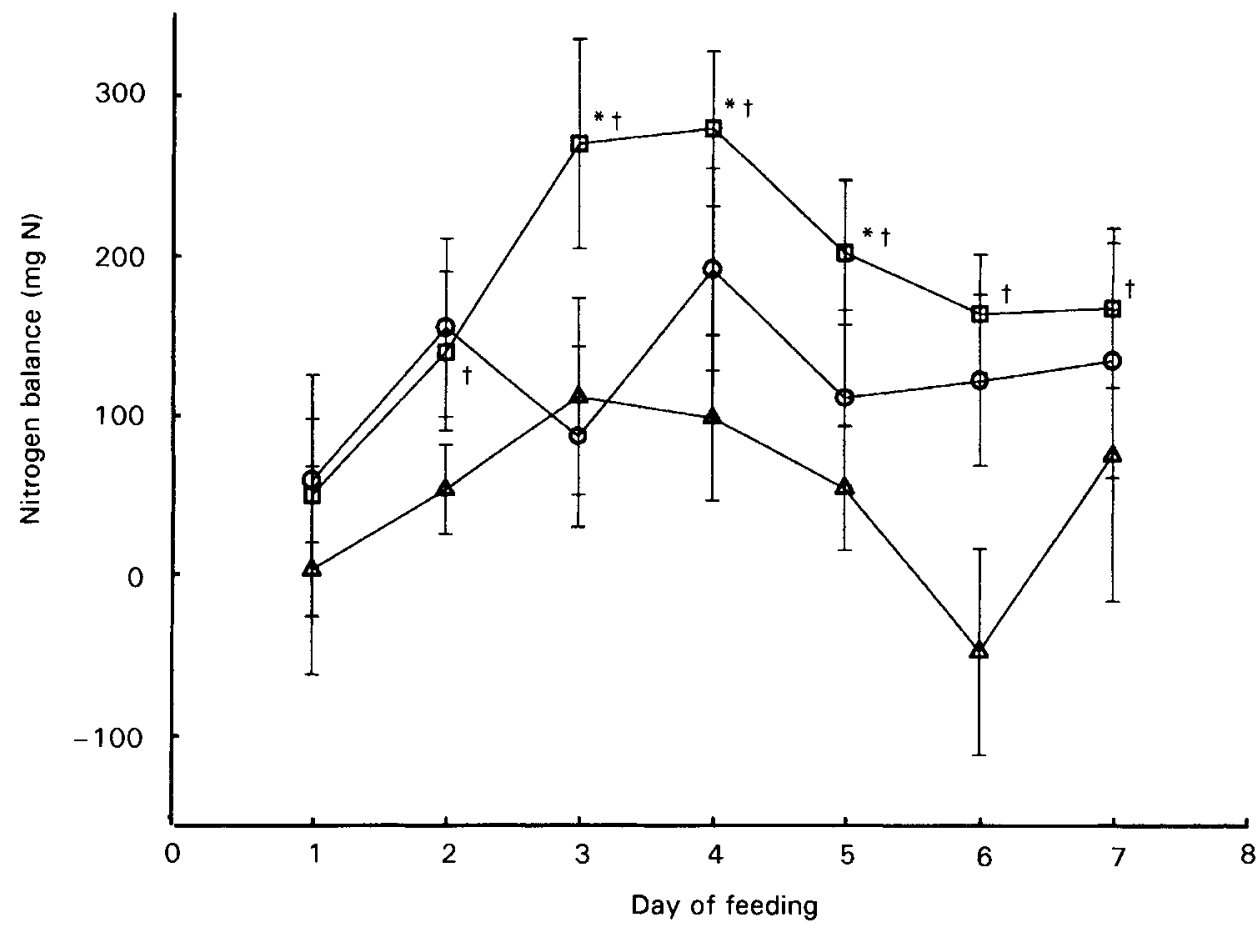

Fig. 9. Daily nitrogen balance, defined as the difference between the total nitrogen intake and urinary nitrogen losses, for groups of rats used to evaluate glyceryl bisacetoacetate infusion for $7 \mathrm{~d}$. Rats were infused with: (O), glucose, ( $\square$ ), glyceryl bisacetoacetate, or $(\triangle)$, saline. Values are means for all surviving rats in a group, with their standard errors represented by vertical bars. Mean values were significantly different from those for the group infused with: *glucose or † saline in day-by-day analysis, $P<0.05$.

toxic impurity left from the preparation or was an inherent property of the compound. It is clear that the toxicity was not due to hyperketonaemia which has been induced using glyceryl monoacetoacetate. In that case the symptoms were urinary hyperketonaemia, hyperglycaemia and polyuria, with death coming in about $48 \mathrm{~h}$. Death in the current rats appeared to be from haemolysis as reported by Leveen et al. (1950) and came within the first $24 \mathrm{~h}$. The cause of death remains unknown.

The compound 1-acetoacetamido-2,3-propane diol was tested with the expectation that stability towards spontaneous hydrolysis and heat sterilization would be improved over its analogue, glyceryl monoacetoacetate. Glyceryl monoacetoacetate undergoes spontaneous hydrolysis in basic solutions and exhibits migration of the acid group from the 1 to the 2 position in acidic solutions. Since the 2-isomer does not appear to be as readily hydrolysed by enzymic catalysis as the 1-isomer (Birkhahn \& Border, 1978), inhibition of migration from the 1 to 2 position would be desirable. Replacement of the $\mathrm{O}$ linkage by a $\mathrm{N}$ linkage could potentially address the two problems simultaneously. Carboxylesterases and/or amidases are available for amide hydrolysis (Heymann, 1980). These carboxylesterases and amidases hydrolyse acyl and aryl amides. Chemical hydrolysis of amide linkages produces an amine and carboxylic acid. Current data suggested that 1-acetoacetamido-2,3propane diol was not readily hydrolysed.

Plasma ketone-body concentrations from the current as well as other investigations support the conclusion that 1-acetoacetamido-2,3-propane diol was poorly hydrolysed. 
Rats infused with 1-acetoacetamido-2,3-propane diol received $32 \mathrm{mmol}$ acetoacetate/d and has plasma acetoacetate, 3-hydroxybutyrate, and total ketone-body concentrations similar to pair-fed, saline-infused rats. The 1-acetoacetamido-2,3-propane diol infusion resulted in an apparent, but not statistically significant, increase of $30 \%$ for acetoacetate and of $38 \%$ for 3-hydroxybutyrate when compared with pair-fed, glucose-infused rats. Previous studies in which glyceryl monoacetoacetate was infused into rats at a rate to provide $23 \mathrm{mmol}$ acetoacetate/d produced a significant $230 \%$ increase in plasma acetoacetate and an insignificant $1 \%$ increase in 3-hydroxybutyrate compared with pair-fed rats (Birkhahn \& Border, 1978). This comparison illustrates the magnitude of plasma ketone-body elevation that might reasonably be expected during the infusion and rapid hydrolysis of an acetoacetate ester. The third part of the current report showed that infusion of glyceryl bisacetoacetate at a rate to provide $24 \mathrm{mmol}$ acetoacetate/d produced a $714 \%$ increase in plasma acetoacetate and a 53\% increase in 3-hydroxybutyrate when compared with values for glucose-infused rats. These data suggest that acetoacetate was not being released from 1-acetoacetamido-2,3-propane diol to any great extent during the infusion period. This finding is consistent with reports that carboxylesterases and/or amidases are more active toward aryl than acyl substrates and are more active with increasingly lipophilic substrates (Heymann, 1980).

Lack of significant energy from 1-acetoacetamido-2,3-propane diol infusion during the present experiment is further supported by the body-weight data. The body weights for rats infused with 1-acetoacetamido-2,3-propane diol were similar to the weights for rats infused with saline, and both rat groups exhibited a tendency towards weight loss. Glucose-infused rats, in contrast, showed a body-weight gain over the $7 \mathrm{~d}$ period. The urinary $\mathrm{N}$ and $\mathrm{N}$ balance data are not in agreement with the body weight or the plasma ketone-body data. However, since we know little about the metabolism and renal clearance of 1acetoacetamido-2,3-propane diol, the $\mathrm{N}$ data can only be considered as difficult to interpret. Our conclusion is that intravenous 1-acetoacetamido-2,3-propane diol does not provide significant metabolic energy and consequently does not make a good intravenous energy substrate.

Glyceryl bisacetoacetate was tested as a follow-up to the successful work with glyceryl monoacetoacetate. Interest in glyceryl bisacetoacetate derives from the higher acetoacetate:glycerol ratio as acetoacetate appears to be a better energy source than glycerol (Birkhahn \& Robertson, 1984). In addition, the presence of a second acetoacetate group in the molecule increases the total energy per molecule although the energy density remains essentially unchanged. Thus, by using glycerol bisacetoacetate, it may be possible to provide a more effective substrate and deliver more energy at a lower osmolality relative to that achieved by glucose or glyceryl monoacetoacetate administration. Glyceryl trisacetoacetate would be the best molecule in terms of energy per osmolal, but it lacks significant water-solubility. The glyceryl bisacetoacetate used in the present study was a mixture of the 1,2- and 1,3-isomers and this may reduce the potential metabolic energy available. Experience with a mixture of 1 - and 2-isomers of glyceryl monoacetoacetate suggested that water-soluble esterases do not remove acids from the ' 2 ' position as readily as from the ' 1 ' position (Birkhahn et al. 1979). Consequently, esters with acetoacetate in the ' 1 ' and ' 3 ' positions may be completely hydrolysed more readily than are esters with acids in the ' 2 ' position. Experimental data on the relative rates of removal of acids from the ' 1 ' and ' 2 ' positions of water-soluble glycerol esters have not been obtained, so this remains somewhat speculative.

The current study indicated that glyceryl bisacetoacetate would be a good intravenous substrate for providing metabolic energy. This conclusion was deduced from the body- 
weight and $\mathrm{N}$ data. The $\mathrm{N}$ data indicated that glyceryl bisacetoacetate was as good as glucose as a N-sparing agent. Glyceryl bisacetoacetate clearly was releasing acetoacetate as evidenced by the elevated plasma acetoacetate and 3-hydroxybutyrate concentrations compared with the values for saline-infused rats. Over all, the results from the infusion of glyceryl bisacetoacetate were similar to results obtained for the infusion of glyceryl monoacetoacetate.

In summary, three compounds containing acetoacetate were synthesized and evaluated for potential use as parenteral nutrients. The partially reduced glucosyl pentaacetoacetate preparation was acutely toxic and lethal either because of an impurity or from an inherent property of the compound. All rats died at the two doses tested. 1-Acetoacetamido-2,3propane diol was not toxic but did not provide significant amounts of metabolic energy. It was judged to be a poor candidate for parenteral feeding. Glyceryl bisacetoacetate was found to support body weight and $\mathrm{N}$ metabolism similar to isoenergetic amounts of glucose and was considered to be a good candidate for providing metabolic energy during parenteral feeding.

This research was funded in part by a grant from Eastman Chemical Co. The authors wish to thank Ms E. Lee and Mr M. H. Chiu for their technical assistance with the handling of the animals and laboratory analysis. A patent has been issued for glyceryl bisacetoacetate as a water-soluble parenteral nutrient in sterile aqueous solution (US Patent No 5,420,335).

\section{REFERENCES}

Bach, A. C. \& Babayan, V. K. (1982). Medium chain triglycerides: an update. American Journal of Clinical Nutrition 36, 950-962.

Bailey, J. W., Barker, R. L. \& Karlstad, M. D. (1992). Total parenteral nutrition with short-chain and long-chain triglycerides - triacetin improves nitrogen balance in rats. Journal of Nutrition 122, 1823-1829.

Birkhahn, R. H. (1982). Experience with alternative fuels. In Advances in Clinical Nutrition, Proceedings of the 2nd International Symposium, pp. 325-337 [I. D. A. Johnston, editor]. Boston, MA: MTP Press.

Birkhahn, R. H., Askari, A. \& Thomford, N. R. (1986). Total parenteral feeding of rats with an acetoacetate monoglyceride and glucose mixture. Journal of Nutrition 116, 851-864.

Birkhahn, R. H., Awad, S., Klaunig, J. E. \& Thomford, N. R. (1989). Interaction of ketosis and liver regeneration in the rat. Journal of Surgical Research 47, 427-432.

Birkhahn, R. H. \& Border, J. R. (1978). Intravenous feeding of the rat with short chain fatty acid esters. II. Monoacetoacetin. American Journal of Clinical Nutrition 31, 436-441.

Birkhahn, R. H. \& Border, J. R. (1981). Alternate or supplemental energy sources. Journal of Parenteral and Enteral Nutrition 5, 24-31.

Birkhahn, R. H., McMenamy, R. H. \& Border, J. R. (1979). Monoglyceryl acetoacetate: a ketone bodycarbohydrate substance for parenteral feeding of the rat. Journal of Nutrition 109, 1168-1174.

Birkhahn, R. H. \& Robertson, L. A. (1984). Parenteral feeding at two hypocaloric levels for comparison of glucose-glycerol mixture with the monoglyceride of acetoacetate on urinary nitrogen losses. Journal of Nutrition 114, 1594-1601.

Border, J. R., Burns, G. P., Rumph, C. \& Schenk, W. G. Sr (1970). Carnitine levels in severe infection and starvation: a possible key to the prolonged catabolic state. Surgery 68, 175-183.

Brennan, M. F., Fitzpatrick, G. F., Cohen, K. H. \& Moore, F. D. (1975). Glycerol: major contributor to the short term protein sparing effect of fat emulsions in normal man. Annals of Surgery 182, 386-394.

Cahill, G. F. (1981). Ketosis. Journal of Parenteral and Enteral Nutrition 5, 281-287.

Clemens, R. J. (1984). The chemistry of the diketene-acetone adduct. Kodak Laboratory Chemical Bulletin 55 , $1-4$.

Desrochers, S., Dubreuil, P., Brunet, J., Jette, M., David, F., Landau, B. R. \& Brunengraber, H. (1995). Metabolism of (R,S)-1,3-butanediol acetoacetate esters, potential parenteral and enteral nutrients in conscious pigs. American Journal of Physiology 268, E660-E667.

Elam, E. U. \& Middleton, M. L. (1985). United States Patent 4,551,523.

Glantz, S. A. (1992). Primer of Bio-statistics, 3rd ed. New York: McGraw-Hill, Inc.

Hauschildt, S., Chalmers, R. A., Lawson, A. M., Schultis, K. \& Watts, R. W. E. (1976). Metabolic investigations after xylitol infusions in human subjects. American Journal of Clinical Nutrition 29, 258-273. 
Heyman, E. (1980). Carboxylesterases and amidases. In Enzymatic Basis of Detoxication, vol. 2, pp. 291-323 [W. B. Jakoby, editor]. New York: Academic Press, Inc.

Holecek, M. \& Simek, J. (1985). Effect of glucose, fructose, sorbitol and amino acid solutions employed in clinical medicine on the development of liver regeneration after partial hepatectomy. Physiologia Bohemoslovaca 34, 395-402.

Kripke, S. A., Fox, A. D., Berman, J. M., Depaula, J., Birkhahn, R. H. \& Rombeau, J. L. (1988). Inhibition of TPN-associated intestinal mucosal atrophy with monoacetoacetin. Journal of Surgical Research 44, 426-444.

Leveen, H. H., Papps, G. \& Restuccia, M. (1950). Problems in the intravenous administration of synthetic and natural fats for nutritional purposes. American Journal of Digestive Diseases 17, $20-24$.

Maiz, A., Moldawer, L. L., Bistrian, B. R., Birkhahn, R. H., Long, C. L. \& Blackburn, G. L. (1985). Monoacetoacetin and protein metabolism during parenteral nutrition in burned rat. Biochemical Journal 226, 43-50.

Nagayama, M., Thomford, N. R. \& Birkhahn, R. H. (1990). Feeding the rat intravenously with ketone bodies following colon anastomosis. Journal of Parenteral and Enteral Nutrition 14, 245-249.

Ulrich, H., Pastores, S. M., Katz, D. P. \& Kvetan, V. (1996). Parenteral use of medium-chain triglycerides: a reappraisal. Nutrition 12, 231-238.

Wells, F. E. \& Smits, B. J. (1978). Utilization and metabolic effects of a solution of amino acids, sorbitol and ethanol in parenteral nutrition. American Journal of Clinical Nutrition 31, 442-450. 